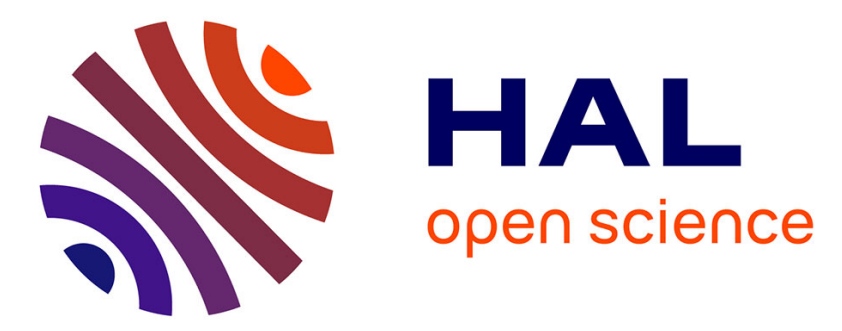

\title{
Metabolome variability for two Mediterranean sponge species of the genus Haliclona: specificity, time, and space
}

Miriam Reverter, Marie-Aude Tribalat, Thierry Pérez, Olivier Thomas

\section{- To cite this version:}

Miriam Reverter, Marie-Aude Tribalat, Thierry Pérez, Olivier Thomas. Metabolome variability for two Mediterranean sponge species of the genus Haliclona: specificity, time, and space. Metabolomics, 2018, 14, pp.1-12/114. 10.1007/s11306-018-1401-5 . hal-01922673

\section{HAL Id: hal-01922673 \\ https://hal.science/hal-01922673}

Submitted on 22 Jan 2019

HAL is a multi-disciplinary open access archive for the deposit and dissemination of scientific research documents, whether they are published or not. The documents may come from teaching and research institutions in France or abroad, or from public or private research centers.
L'archive ouverte pluridisciplinaire HAL, est destinée au dépôt et à la diffusion de documents scientifiques de niveau recherche, publiés ou non, émanant des établissements d'enseignement et de recherche français ou étrangers, des laboratoires publics ou privés. 


\section{Metabolome variability for two Mediterranean sponge species of the genus Haliclona: specificity, time, and space}

Miriam Reverter,

Email MIRIAM.REVERTER@nuigalway.ie

Marie-Aude Tribalat, 2

Email marieaude.tribalat@gmail.com

Thierry Pérez, 3

Email thierry.perez@imbe.fr

Olivier P. Thomas, $1,2 \square$

Email Olivier.thomas@nuigalway.ie

1 Marine Biodiscovery, School of Chemistry and Ryan Institute, National University of Ireland Galway (NUI Galway), University Road, Galway, H91 TK33 Ireland

2 Geoazur, UMR Université Nice Sophia Antipolis-CNRS-IRDOCA, 06560 Valbonne, France

3 Institut Méditerranéen de Biodiversité et d'Ecologie marine et continentale (IMBE), CNRS, IRD, Aix Marseille Université, Université Avignon, Station Marine d'Endoume, Rue de la Batterie des Lions, Marseille, France

Received: 27 February 2018 / Accepted: 25 July 2018

\section{Abstract}

\section{Introduction}

The study of natural variation of metabolites brings valuable information on the physiological state of the organisms as well as their phenotypic traits. In marine organisms, metabolome variability has mostly been addressed through targeted studies on metabolites of ecological or pharmaceutical interest. 
However, comparative metabolomics has demonstrated its potential to address the overall and complex metabolic variability of organisms.

\section{Objectives}

In this study, the intraspecific (temporal and spatial) variability of two Mediterranean Haliclona sponges (H. fulva and H. mucosa) was investigated through an untargeted and then targeted metabolomics approach and further compared to their interspecific variability.

\section{Methods}

Samples of both species were collected monthly during 1 year in the coralligenous habitat of the Northwestern Mediterranean sae at Marseille and Nice. Their metabolomic profiles were obtained by UHPLC-QqToF analyses.

\section{Results}

Marked variations were noticed in April and May for both species including a decrease in Shannon's diversity and concentration in specialized metabolites together with an increase in fatty acids and lyso-PAF like molecules. Spatial variations across different sampling sites could also be observed for both species, however in a lesser extent.

\section{Conclusions}

Synchronous metabolic changes possibly triggered by physiological factors like reproduction and/or environmental factors like an increase in the water temperature were highlighted for both Mediterranean Haliclona species inhabiting close habitats but displaying different biosynthetic pathways. Despite significative intraspecific variations, metabolomic variability remains minor when compared to interspecific variations for these congenerous species, therefore suggesting the predominance of genetic information of the holobiont in the observed metabolome.

\section{Keywords}

Marine environment

Sponges

Haliclona

Spatio-temporal variability 
Interspecific variability

Specialized metabolites

\section{Electronic supplementary material}

The online version of this article (https://doi.org/10.1007/s11306-018-1401-5) contains supplementary material, which is available to authorized users.

\section{Introduction}

Metabolites are the products of metabolic reactions within an organism and their levels reflect the response of biological systems to physiological and environmental changes. The metabolome represents a snapshot of the metabolites present in an organism at a given time and will change according to different life stages and environmental conditions (Kosmides et al. 2013; Goulitquer et al. 2012). The variability of the metabolome can bring very useful information in ecology but also in systems biology. For instance, studying the natural variation of metabolites proved to be useful in unravelling the evolution of phenotypic traits in terrestrial plants (Li et al. 2015; Routaboul et al. 2012). In marine organisms, study of metabolome variability mostly focused on so-called secondary or specialized metabolites (Kuhlisch and Pohnert 2015), low molecular weight $(<1500 \mathrm{Da})$ molecules playing key roles in various ecological processes (Agrawal et al. 2012; Ferrer and Zimmer 2013, 2012). These metabolites being involved in chemical mediation between organisms, their variation does not only affect the resilience of one species but it can have cascading effects on the networks of interactions (Hay 2014; Bornancin et al. 2017). Intraspecific variation of metabolites with time and space is crucial for understanding species ecology and ecosystem functioning (Paul et al. 2007; Glassmire et al. 2016).

In the marine environment, spatial and temporal variations of specialized metabolites have been studied in algae (Payo et al. 2011; Soares et al. 2015), cnidarians (Kelman et al. 2000; He et al. 2014; Costa-Lotufo et al. 2018), tunicates (López-Legentil et al. 2006), bryozoans (Peters et al. 2004) and sponges (Reverter et al. 2016; Ternon et al. 2017; Sacristan-Soriano et al. 2011). Spatial variation of metabolites has been mostly related to local adaptation to the environment and fluctuating parameters such as temperature, light, or chlorophyll concentrations. In a recent study, Soares et al. (2015) found different chemotypes of the brown alga Stypopodium zonale in different geographic locations, probably indicative of genotypic sorting across habitats. Seasonal changes of specialized metabolites possibly related to changes of environmental parameters such as temperature have been observed in some marine 
invertebrates (Page et al. 2005; Sacristán-Soriano et al. 2012; Ternon et al. 2017). According to the optimal defence theory (ODT) (Rhoades 1985), the energy allocated to the biosynthesis of specialized metabolites results from the continual trade-off with the energy invested in primary functions such as growth and reproduction. Several studies on marine invertebrates have indeed shown a decrease in the production of specialized metabolites during reproduction (López-Legentil et al. 2007; Ivanisevic et al. 2011). However, this phenomenon may not be universal in all marine invertebrates, and might be related to the reproduction strategy and associated metabolic cost (Reverter et al. 2016).

Sponges (phylum Porifera) are important components of benthic communities worldwide where they play major roles in some ecosystem functioning like the Caribbean Sea or the Central Indo-Pacific (de Goeij et al. 2013; Haas et al. 2016). Sponges are also well known to produce a large diversity of bioactive specialized metabolites that confer protection against predators and pathogens and advantage against competitors (Proksch 1994; Hay 2009; Blunt et al. 2017; Loh and Pawlik 2014). Within the class Demospongiae, several sponges of the order Haplosclerida are considered as prolific sources of bioactive marine natural products. In particular, species from the genus Haliclona (family Chalinidae) have attracted much attention due to the high diversity of species and the variety of specialized metabolites they contain (Tribalat et al. 2016). Importantly, the systematics of this genus and more generally the Haplosclerida group is being revised deeply. Haliclona species are found throughout the Mediterranean, from intertidal to continental shelf habitats $(2$ to $>100 \mathrm{~m})$ (Santín et al. 2017).

In this study we focused on the Mediterranean species Haliclona fulva and Haliclona mucosa, two sponge species found in shallow waters $(10-50 \mathrm{~m})$ in semi-dark conditions. Haliclona (Halichoclona) fulva is known to produce several acetylenic compounds (renierins, fulvinol, and fulvynes) and sesquiterpenes (fulvanins) (Cimino and De Stefano 1977; Casapullo et al. 1993; Ortega et al. 1996; Nuzzo et al. 2012). Recently, cladocroic acid and the diastereomer 3-epicladocroic acid were also isolated from H. fulva (Genta-Jouve and Thomas 2013). H. mucosa (subgenus Soestella) is known to produce sesquiterpenes hydroquinones from the panicein family (Zubía et al. 1994) and the bicyclic eicosanoid mucosin (Casapullo et al. 1997). Thus, these two species, phylogenetically related and living in the same environment, produce totally different families of specialized metabolites. The objective of this study was (1) to assess the intra-specific variability (temporal and spatial) of these two species metabolomes, in order to investigate if despite their different biosynthetic pathways they display similar patterns of variation and (2) to evaluate which type of intra-specific variation is more important (spatial or temporal) and their 
relative contribution when compared to inter-specific variation. To reach these objectives, we first deployed a non-targeted UHPLC-HRMS metabolomics approach to investigate patterns of metabolome variability.

\section{Materials and methods}

\subsection{Biological material}

Specimens of Haliclona fulva and Haliclona mucosa were collected by SCUBA between 20 and $25 \mathrm{~m}$ depth in the Northwestern Mediterranean Sea. For the temporal variability, 6 individuals of each species were collected monthly at the Grotte du Lido in the bay of Villefranche-sur-Mer (N434ㄴ $30.0^{\prime \prime}$, E7 $\left.7^{\circ} 19^{\prime} 11.9^{\prime \prime}\right)$ from April 2014 until March 2015. For the spatial variability, H. mucosa was also sampled in Grotte de Jarre (N43 $11^{\prime} 52.0^{\prime \prime}$, E5 $\left.5^{\circ} 21^{\prime} 53.8^{\prime \prime} ; \mathrm{n}=4\right)$ and Riou Caramasseigne (N4310'19.3'; E5 23'37.4'; $\mathrm{n}=3$ ) near Marseille and H. fulva in the Grotte de Jarre (Marseille, $\mathrm{n}=3$ ) and Monaco (N43'43'34.9', E7 ${ }^{\circ} 25^{\prime} 15.2^{\prime}$ $' ; n=4$ ) in August 2014 (Supp. Fig. S1). Samples were immediately frozen at $20{ }^{\circ} \mathrm{C}$, freeze-dried and stored dry at $-20{ }^{\circ} \mathrm{C}$ until extraction.

\section{Fig. 1}

Shannon's diversity indices of $H$. fulva and $H$. mucosa metabolomes sampled at different months 

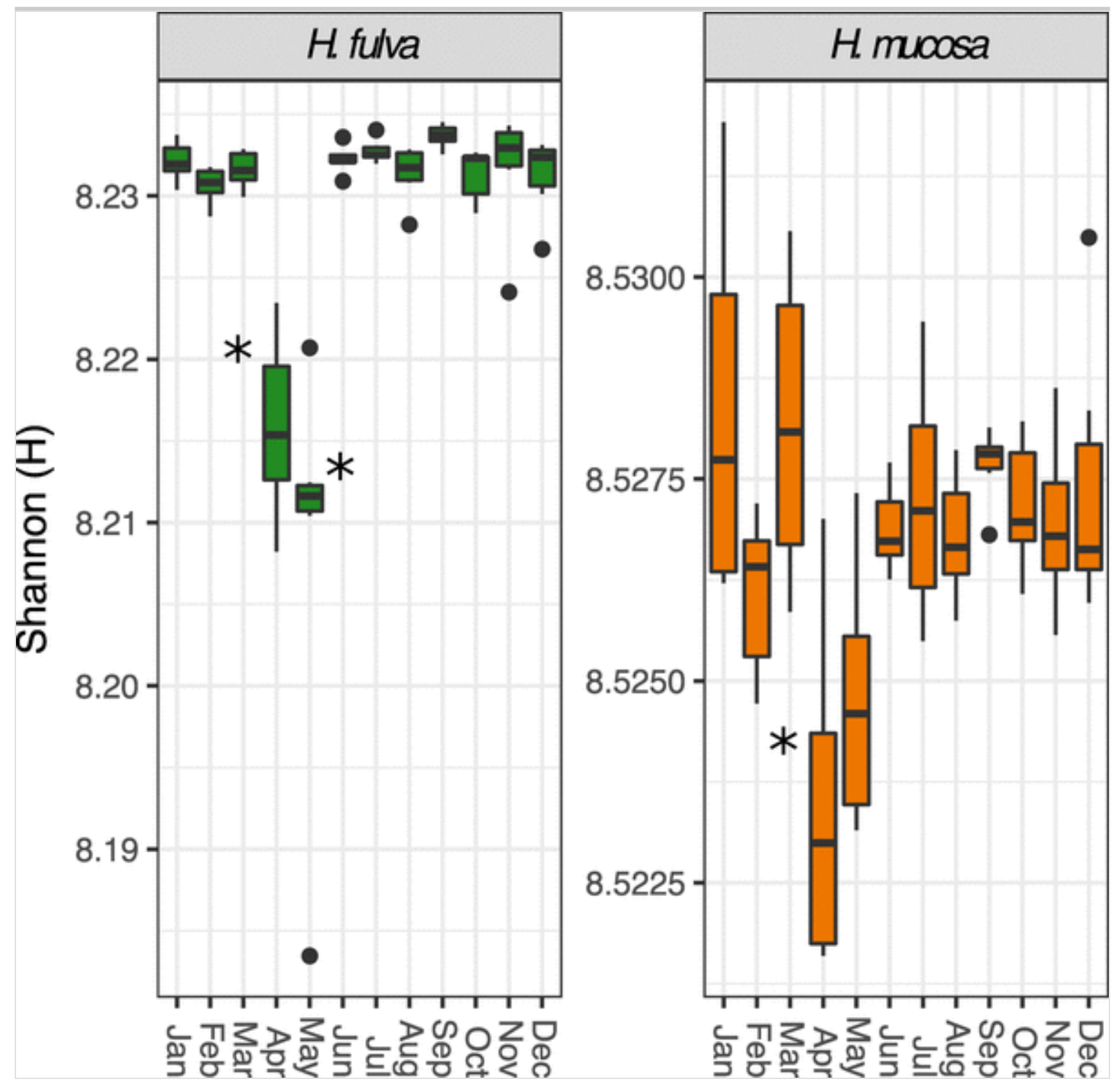

\subsection{Chemical extraction}

The freeze-dried samples were first ground to obtain a homogeneous powder. A mass of $250 \mathrm{mg}$ of powder was extracted 3 times in $5 \mathrm{~mL}$ of a mixture methanol/dichloromethane (1:1) for $5 \mathrm{~min}$ in an ultrasonic bath. The combined organic extracts were centrifuged $10 \mathrm{~min}$ at $2000 \mathrm{rpm}$ and the supernatant was collected carefully and dried using a Speedvac. The extracts were dissolved in $5 \mathrm{~mL}$ of methanol and stored at $4{ }^{\circ} \mathrm{C}$ for $24 \mathrm{~h}$. A volume of $0.1 \mathrm{~mL}$ of the supernatant was then filtered through $0.2 \mu \mathrm{m}$ polytetrafluoroethylene (PTFE) and diluted with 0.9 methanol for the UHPLC-MS analysis. The quality control (QC) samples were prepared by pooling small aliquots from all extracts.

\subsection{UHPLC-HRMS analyses}

UHPLC-HRMS analyses were performed with a UHPLC-DAD equipped with an Ultimate 3000 (ThermoScientific, MA, USA) connected to a qToF Impact II 
mass spectrometer (Bruker). Chromatographic separation was achieved on a Nucleodur ${ }^{\circledR}$ Phenyl-hexyl column $(100 \times 4.6$ mm, $1.8 \mu \mathrm{m}$, Macherey-Nagel, Germany) using a linear elution gradient of $\mathrm{H}_{2} \mathrm{O} /$ Acetonitrile both solvents containing $0.01 \mathrm{M}$ ammonium formate and 0.1\% formic acid, from 95:5 (v/v) to $0: 100(\mathrm{v} / \mathrm{v})$ in $12 \mathrm{~min}$ followed by $5 \mathrm{~min}$ at 100\% acetonitrile. Mass spectra were acquired in positive mode with an elution flow $0.5 \mathrm{~mL} \mathrm{~min}^{-1}$ and a constant column temperature of $40^{\circ} \mathrm{C}$. Injection volume was set to $10 \mathrm{~L}$. The mass spectrometer analyser parameters were set as follows: nebulizer sheath gas, $\mathrm{N}_{2}$ (44 psi); dry gas, $\mathrm{N}_{2}$ (12 L/min); capillary temperature, $200{ }^{\circ} \mathrm{C}$; capillary voltage, $2500 \mathrm{~V}$; collision energy, $4 \mathrm{eV}$ and a full-scan mass window of 50$1200 \mathrm{~m} / \mathrm{z}$. Samples sequence was randomized to reduce systematic error associated with instrumental drift. QC (pool) and blank (MeOH) samples were injected at the beginning, the end and equidistantly throughout the sequence. AQ1

Metabolomics data have been deposited to the EMBL-EBI MetaboLights database (https://doi.org/10.1093/nar/gks1004. PubMed PMID: 23109552) with the identifier MTBLS638.

The complete dataset can be accessed here https://www.ebi.ac.uk/metabolights/MTBLS638.

\subsection{Data treatment and statistical analysis}

LC-MS raw data files were converted to mzML files using the open-source msConvert tool from the ProteoWizard library (Kessner et al. 2008). mzML files were processed using the R package XCMS (R version 3.3.1., XCMS version 1.50.0) to detect, deconvolute and align features (molecular entities with a unique $\mathrm{m} / \mathrm{z}$ and a specific retention time). Parameter for XCMS processing were set as described in Patti et al. (2012) for UPLC-QTOF (high resolution). XCMS analysis of these data provided a matrix containing the retention time, $\mathrm{m} / \mathrm{z}$ value and integrated peak areas of the identified features. Finally, only features with a coefficient of variation less than $20 \%$ among the QC samples were kept for further data analyses. Data were normalized by log transformation prior to statistical analysis.

Metabolite diversity of each sample was determined by the Shannon's diversity index (H). ANOVA test and Tukey's HSD post-hoc test were used to detect temporal and spatial differences in metabolite diversities of both species. Principal Component Analysis (PCA) was used to visualize the spatial and temporal (monthly) variability of both sponge metabolomes. Specialized metabolites were annotated with an in-house library of metabolites from $H$. fulva 
and H. mucosa, and variation of their expression level tested with KruskalWallis non parametric analysis and Kruskal post-hoc test (package pgirmess for R). The multivariate Partial Least Squares Discriminant Analysis (PLS-DA) was used to select the metabolites driving the spatial and temporal differences observed. PLS-DA model accuracy was calculated using a two-fold crossvalidation $(2 \mathrm{CV})$ and the resulting number of misclassifications (NMC) was compared to its permutated null distribution (999 permutations) to test for model significance $(\mathrm{P}$ value $<0.05)$. Variable Importance in Projection (VIP) were obtained (package RV AideMemoire for R), and features with VIP scores higher than 1 were retained. Further selection of VIPs was performed based on their intensities (threshold of 10.000 at least in two replicates). Kruskal-Wallis test and Kruskal post-hoc test were used to test for significant differences between the different groups (the two different temporal periods detected: 1: April and May and 2: the rest of the months). Putative identification of selected VIPs was performed by searching the exact mass in Metlin (https://metlin.scripps.edu/) with 5 ppm accuracy, comparing with standards present in our laboratory and comparing with published literature on sponge lipids.

Finally, a multiple regression tree (package mvpart in R) was used to study the relative importance of inter-specific variability, temporal and spatial intraspecific variability of the Haliclona metabolomes. MRT allows ranking of factors according to their contribution by producing a tree where at each split data is partitioned into two mutually exclusive groups, each of which is as homogeneous as possible, displaying this way the major factors determining the variability (De'ath 2002). Only factors with a contribution higher than $0.1 \%$ were plotted.

\section{Results}

\subsection{Temporal variability}

The metabolome diversity (Shannon index, H) of H. fulva decreased significantly in April and May $(\mathrm{P}<0.001)$ (Fig. 1). A decreased metabolite diversity was also observed for H. mucosa in April (significantly lower diversity, $\mathrm{P}<0.001$, in April than the rest of months but February and May) and May (significantly lower diversity, $\mathrm{P}<0.001$, than January, March and September) (Fig. 1a).

PCA showed significant differences in the metabolome composition of both Haliclona species between April and May and the rest of the months (PERMANOVA, P <0.001) (Fig. 2). 
Fig. 2

Principal components analysis (PCA) score plots of H. fulva (a) and H. mucosa (b) on the first two components ( $\mathrm{PC} 1$ and $\mathrm{PC} 2$ ). Shape represents seasons (winter: Dec, Jan, Feb; spring: Mar, Apr, May; summer: Jun, Jul, Aug; Autumn: Sept, Oct, Dec) and the colors indicate different months
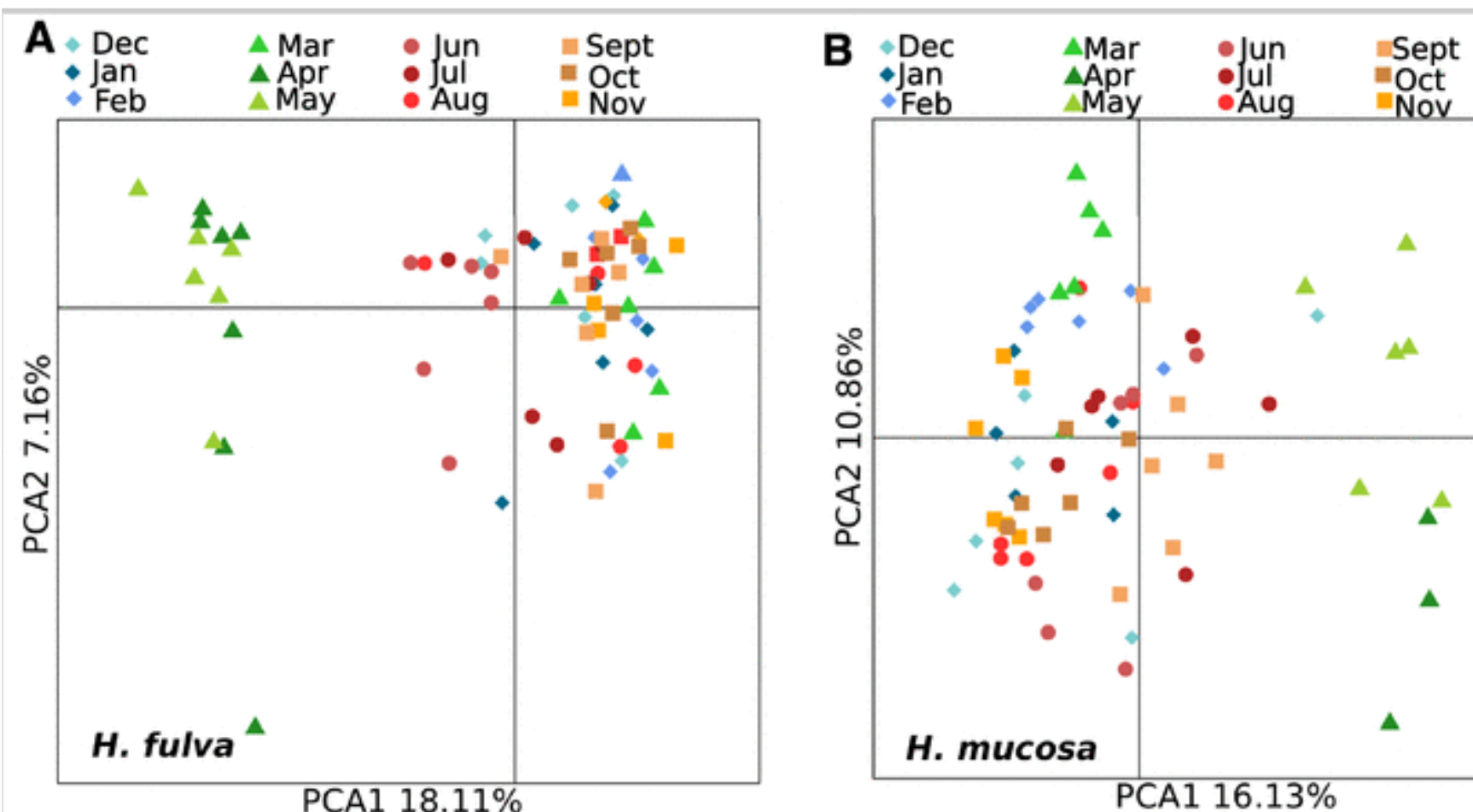

PCA1 $18.11 \%$

PCA1 $16.13 \%$

Our in-house library of specialized metabolites allowed identification of several features in both sponges based on the comparison between MS spectra and retention times. A total of 10 known metabolites from $H$. fulva were assigned: renierin 1 modified structure (acid 17-bromo-6-hydroxytricosa-16-ene-2,4dinoic (Tribalat 2016)), 18-dihydrorenierin 1, cladocroic acid and fulvynes A-G (found as dicharged ions, see supplementary information). Eight paniceins of our chemical library (A, A hydroquinone, B2, B3, C, D, F1 and F2) were identified in H. mucosa extracts (See supplementary information). All identified metabolites from both sponges significantly decreased in April and May $(\mathrm{P}<$ 0.001) (Fig. 3). We were also able to putatively annotate some families of other metabolites based on their isotopic profile and/or fragmentation patterns like lysophospholipids, peptides or fatty acids. However, a clear identification was not sought as our work is mainly focused on the variability of specialized metabolites.

Fig. 3 
Identified specialized metabolites in the metabolomes of $H$. fulva (a) and $H$. mucosa (b). Size of bubbles represents the peak area of the feature in the LC-MS chromatogram obtained by XCMS

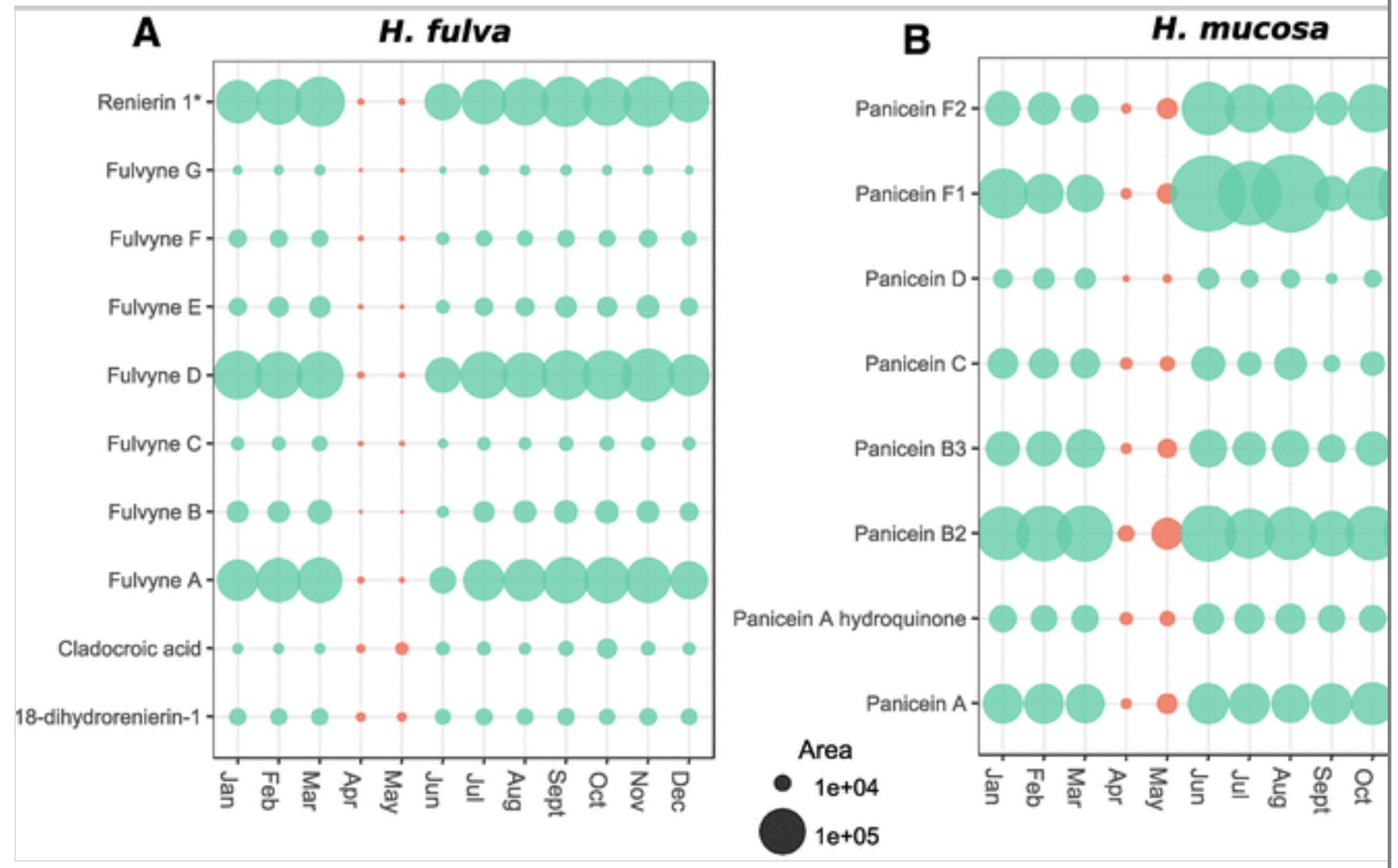

The PLS-DA models accurately predicted differences between the metabolomic profiles of April and May and the rest of the months for both sponge species $\left(\mathrm{NMC}_{H . f u l v a}=0, \mathrm{P}_{\text {H.fulva }}=0.001 ; \mathrm{NMC}_{\text {H.mucosa }}=0, \mathrm{P}_{\text {H.mucosa }}=0.001\right)$. After cleaning the matrix (removal of isotopes and adducts), 133 features in H. fulva and 202 in $H$. mucosa were highlighted with a VIP score higher than 1 and minimum fold-change of 2, and significantly over or under-expressed in AprilMay (Kruskal-Wallis, $\mathrm{P}<0.001$ ). Putative annotation of metabolites using Metlin and the in-house built library allowed the assignment of the families of 75 metabolites in H. fulva and 30 in H. mucosa.

A total of 38 metabolites were overexpressed in H. fulva in April and May, which included 11 brominated non polar compounds (assigned through their characteristic isotopic pattern), 11 fatty acids and one lysophospholipid (lysoPAF like molecule). From the 95 metabolites that significantly decreased in April and May in H. fulva, 8 were specialized metabolites identified in our chemical library (6 fulvynes and two renierins), 42 minor doubly charged metabolites with similar masses and retention times than fulvynes $(m / z \sim 400 \mathrm{Da}$, $\mathrm{RT} \sim 500 \mathrm{~s}$ ), two fatty acids and four peptides (found as triply charged ions with monoisotopic masses 1600-2000 Da) (Fig. 4A). 
Fig. 4

Over-expressed and under-expressed metabolites in each of the sponge species (a: H. fulva; b: H. mucosa) plotted according to their retention time (x axis) and exact mass (y axis)
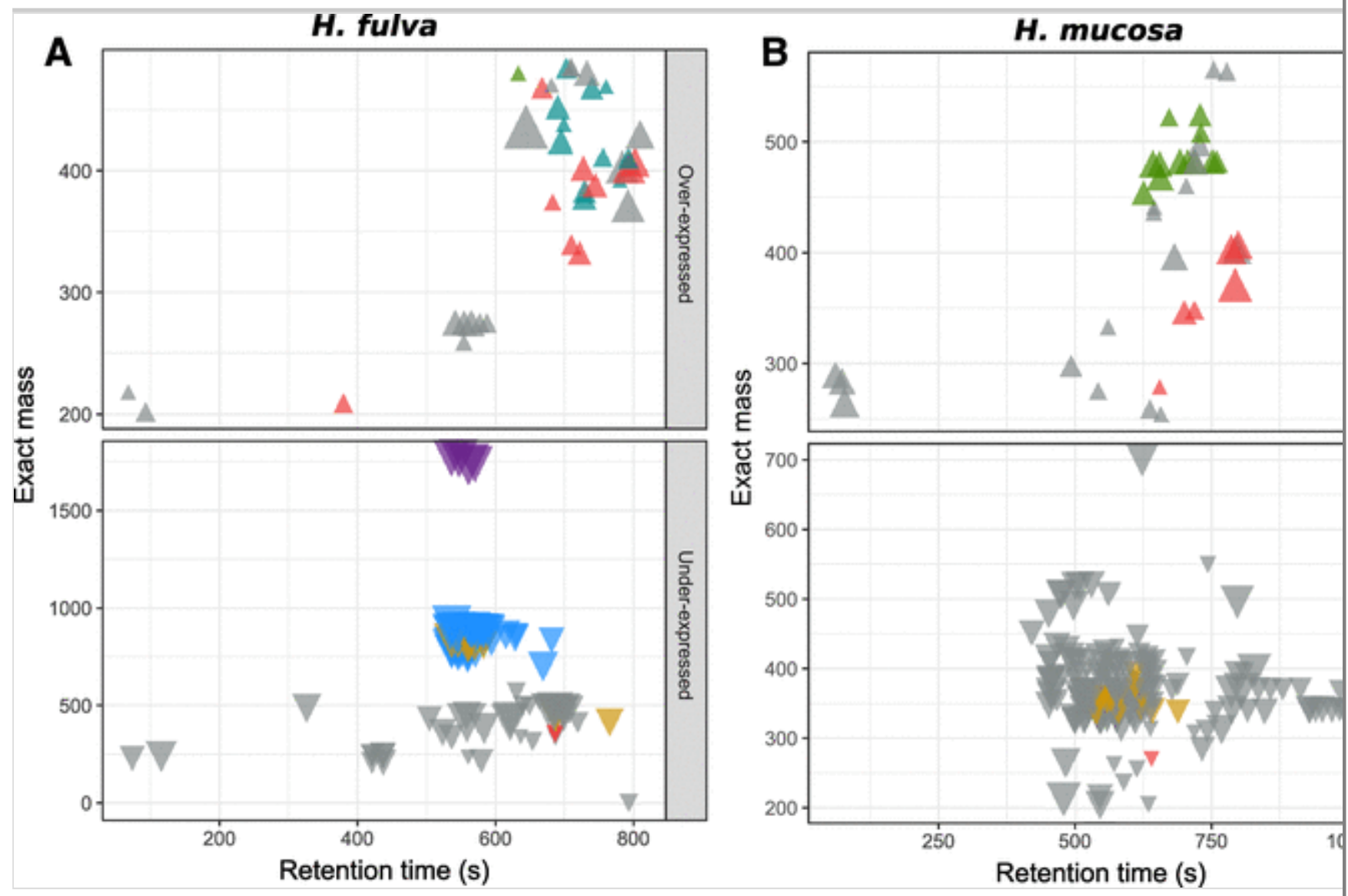

In $H$. mucosa 35 metabolites were overexpressed, 12 of which were putatively annotated as lysophospholipids (lyso-PAF derivatives) and 6 as fatty acids. 167 metabolites significantly decreased in April and May, including 8 paniceins present in our chemical library, one fatty acid and the rest unknowns (Fig. 4b). Six metabolites were overexpressed in both Haliclona species, 2 of which were putatively annotated as fatty acids.

\subsection{Spatial variability}

Metabolomic profiles of $H$. fulva did not present significant differences between the studied sites (Marseille, Monaco, and Villefranche-sur-Mer) (Fig. 5a). H. mucosa samples from Riou Caramasseigne are significantly different from samples from Villefranche-sur-Mer and Grotte de Jarre $(\mathrm{P}<0.001)$ (Fig. 5a).

Fig. 5 
Shannon's diversity indices of $H$. fulva and $H$. mucosa metabolomes sampled at different locations (a). Principal components analysis (PCA) score plots of $H$. fulva (b) and H. mucosa (c) metabolomes sampled at different locations on the first two components (PC1 and PC2)
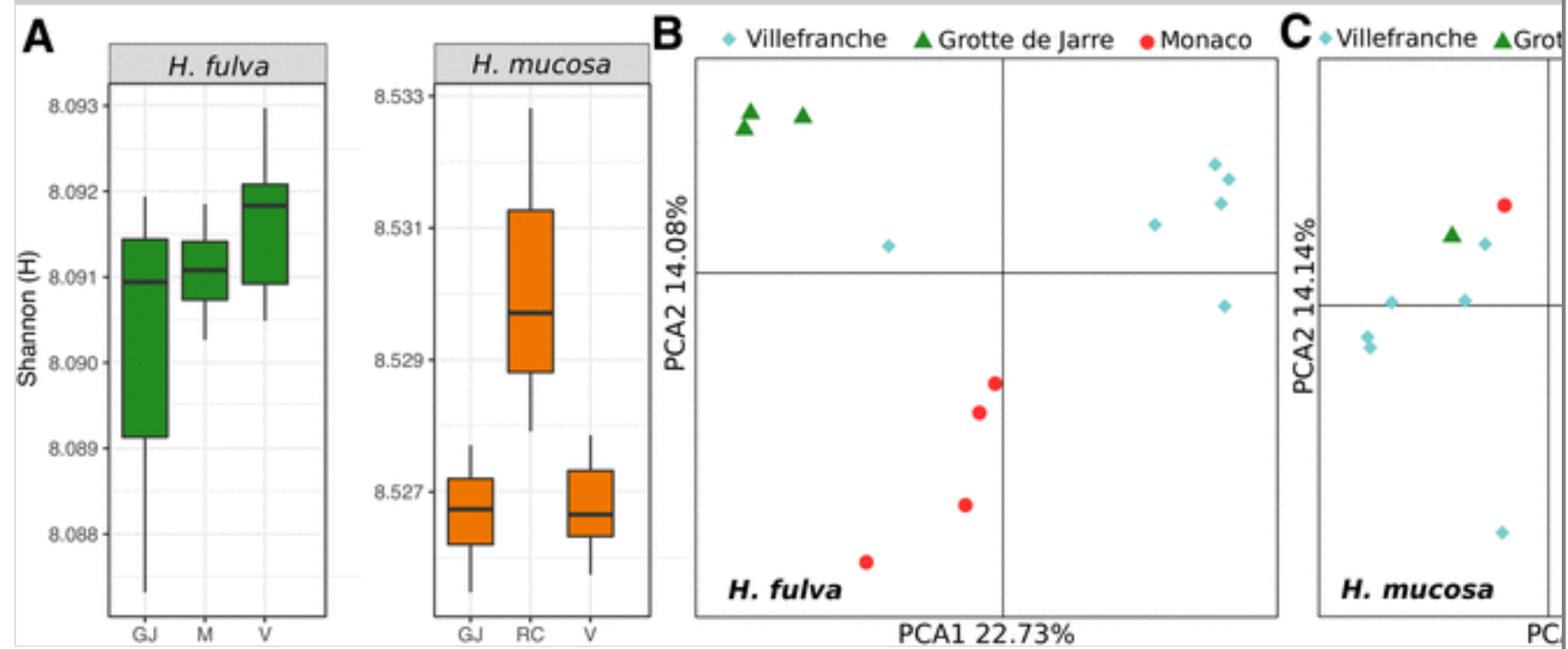

PCA showed significant differences in the metabolome composition of both Haliclona species sampled at different sites (PERMANOVA, $\mathrm{P}_{H .}$ fulva $=0.002$, $\mathrm{P}_{H \cdot \text { mucosa }}=0.02$ ) (Fig. 5b, c). However, these differences were not affected by the geographic distance between the sites. H. fulva samples from Villefranche and Monaco ( $9 \mathrm{~km}$ distance) were not significantly more similar than samples from Grotte de Jarre (167 km away from Villefranche). Similarly, H. mucosa samples from Grotte de Jarre and Riou Caramasseigne (4 km distance) did not show more similar metabolome compositions than Villefranche.

The PLS-DA model was appropriate to predict metabolite differences in H. fulva between different sampling sites $\left(\mathrm{NMC}_{H . f u l v a}=0.09, \mathrm{P}_{H . f u l v a}=0.001\right)$. However, it could not predict accurately the metabolite differences in H. mucosa in different sampling sites $\left(\mathrm{NMC}_{\text {H.mucosa }}=0.33, \mathrm{P}_{\text {H.mucosa }}=0.032\right)$. In consequence, only the VIP from the H. fulva spatial study were obtained. None of the specialized metabolites identified in neither H. fulva nor H. mucosa displayed significant differences among the different sampling sites.

\subsection{Intra-specific versus inter-specific variability}

A MRT analysis was conducted to assess the relative importance of inter-specific variability and the two types of intra-specific variability studied (temporal and spatial) on the variations of the sponges metabolomes. Results show that $97.72 \%$ of the differences observed in the sponge metabolomes are explained by the 
species (H. mucosa and $H$. fulva). Temporal variability (differences between April and May and the rest of the months) was the second source of variability in both sponge species, accounting for $0.2 \%$ in $H$. mucosa and $0.3 \%$ in $H$. fulva (Fig. 6). Spatial variation accounted for less than $0.1 \%$ of the total metabolome variability and therefore it was not plotted in the MRT.

\section{Fig. 6}

Multiple regression tree of the $H$. fulva and H. mucosa metabolomes (both temporal and spatial samples) with the $\%$ of variance explained by each split

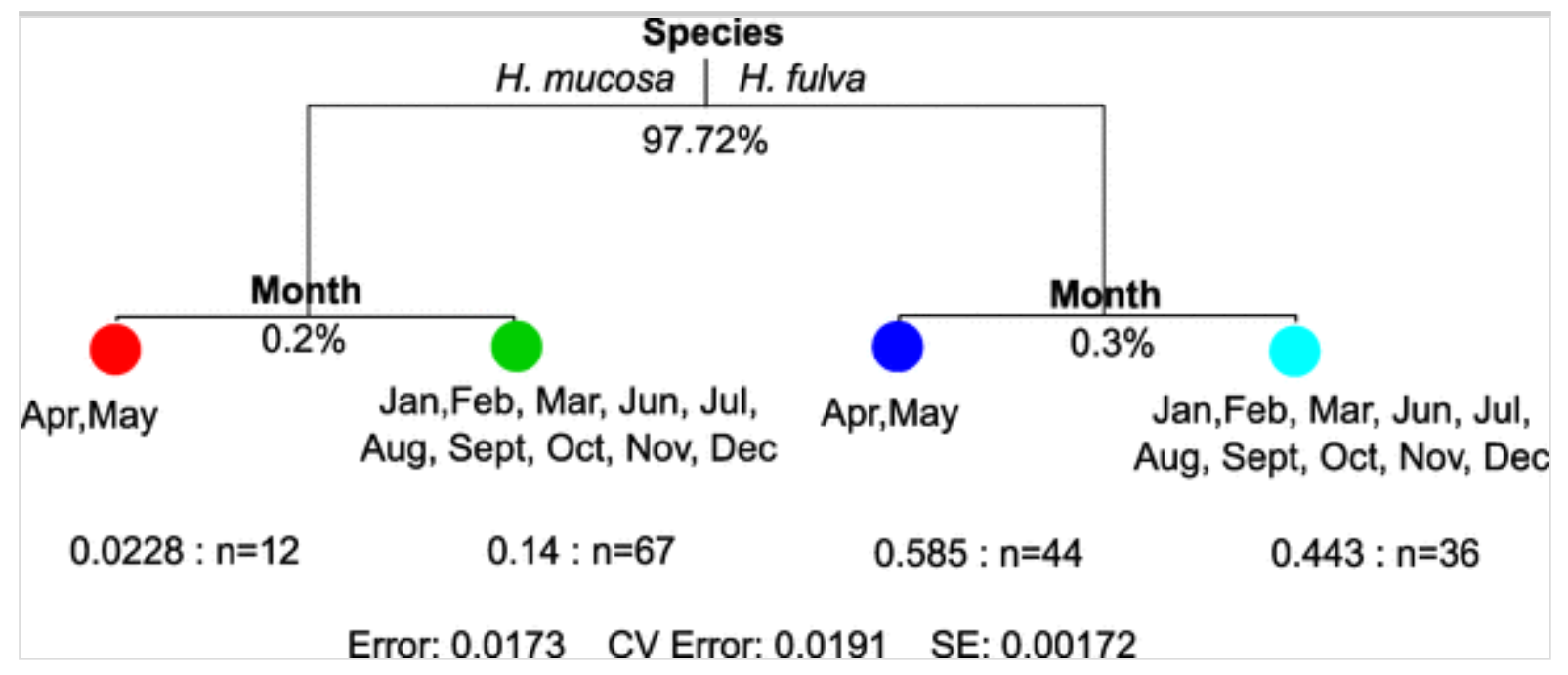

\section{Discussion}

The use of comparative metabolomics in the study of intra-specific variabilities provides numerous advantages compared to classical targeted studies (Kuhlisch and Pohnert 2015). Metabolic responses of organisms are highly complex and therefore a comprehensive study of the metabolome is required to capture the whole variability and its biologic implications. So far, most studies on metabolomic variabilities of marine invertebrates were performed using targeted approaches (Sacristán-Soriano et al. 2012; Duckworth et al. 2012; Reverter et al. 2016). Although these studies have the advantage of being quantitative, they explore only a very limited part of the metabolism. Conversely, comparative metabolomics, has the potential to study and uncover previously unidentified metabolites with important biological and ecological roles (Kuhlisch and Pohnert 2015). This study on the spatio-temporal variability of two Mediterranean Haliclona metabolomes using a comparative LC-MS metabolomics approach showed significant changes in the metabolomic profiles of both species occurring in spring (April and May). As highlighted in previous similar researches on sponge metabolomes (e.g. Ivanisevic et al. 2011), the life cycle may explain at least part of the detected variation. The life cycle of $H$. 
fulva has been recently characterised, and a shift from asexual to sexual reproduction has been reported in early April (Ereskovsky et al. 2017). We therefore hypothesize that this reproduction shift induces a change in the metabolite content as reflected for both sponges metabolomes in April and May. The significant decrease in the specialized metabolites of both species is in accordance with the ODT theory, indicating an investment towards the start of the sexual reproduction cycle. For both H. fulva and H. mucosa, this shift occurs only at the early stages of sexual reproduction when the animal needs to trigger the development of sexual gametes, and not throughout all the gametogenesis process, which in H. fulva lasts until September (Ereskovsky et al. 2017). Tradeoff between the production of specialized metabolites and reproduction has been previously reported in the homoscleromorph sponge Oscarella balibaloi, however in this case it was observed at the peak of the reproductive effort (Ivanisevic et al. 2011). The increase in fatty acids and lysophospholipids would also be concurrent with the start of reproduction. Fatty acids are important for cell metabolism and are involved in multiple signalling roles in reproduction and early developmental processes (Vrablik and Watts 2013; Stanley 2000). Physiological roles of lysophospholipids (LPLs) from marine invertebrates remain mostly unknown (Sugiura et al. 1992; Nishikawa et al. 2015). Some studies suggest that LPLs might play a role in invertebrate defence and several phosphatidylcholines and lyso-PAF (Platelet Activating Factor) derivatives isolated from sponges display biological activities such as cytotoxicity, antibacterial, antifungal and antifouling (Müller et al. 2004; Alam et al. 2001; Shin et al. 1999; Lin et al. 2015; Zhao et al. 2003; Butler et al. 1996). Interestingly, Ivanišević et al. (2011) also observed that level of two bioactive LPLs increased in reproductive sponges suggesting that LPLs could play a role in sponge embryogenesis and morphogenesis.

Sponges are a prolific source of specialized metabolites including rare fatty acid derivatives such as brominated acetylenic acids (Pham et al. 1999; Aoki et al. 2013; Ohta et al. 2013; Dembitsky et al. 2003). Several brominated fatty acids were described from Haliclona sponges (Alarif Walied et al. 2013; Aratake et al. 2009) including renierins from H. fulva (Cimino and De Stefano 1977). In this study, eleven unknown brominated non polar compounds were found overexpressed in H. fulva in April and May, while the concentrations of most of the known renierins identified in our chemical library plummeted. Specialized metabolites can experiment enzymatic bioconversion to best serve the organism's physiological and ecological needs. For example, bioconversion of metabolites into more active ones is well reported in terrestrial and marine organisms following mechanical damage, which is known as activation of chemical defenses (Pohnert 2004; Paul and Van Alstyne 1992). Bioconversion of metabolites in marine invertebrates related to reproduction has not been reported 
to date, although this could have passed unnoticed by targeted studies or untargeted approaches which failed to characterize the whole chemical diversity. The decrease of renierins and increase in unknown brominated non polar compounds with similar retention times could indicate the biotransformation of renierins. However, correlation between renierins and the brominated non polar compounds is not well supported. More research is needed to elucidate the structures of these brominated compounds and understand their biological role in the sponge, biosynthesis, and putative contribution to reproduction.

Although $H$. mucosa and $H$. fulva possess specialized metabolites from different biosynthethic pathways, we observed similar changes in the composition of the metabolome, characterized by an overall decrease in the concentration of specialized metabolites in April and May for both species. Furthermore, both species experienced an increase in fatty acids and lysophospholipids in this period of the year, and 6 common metabolites were putatively annotated, two of them as fatty acids. These similar variation patterns suggest a similar metabolic response in both species. $H$. mucosa life cycle has not yet been established, but it will be interesting to study whether there is a reproduction shift in April and May as observed in H. fulva. There is still a debate whether changing environmental conditions such as temperature produces variations in the production of specialized metabolites. Several studies have found higher concentrations of specialized metabolites in summer corresponding to maximum yearly temperatures (Abdo et al. 2007; Ternon et al. 2017; De Caralt et al. 2013) while other studies failed to find seasonal changes in production of metabolites (Duckworth et al. 2012; López-Legentil et al. 2006). In this study, a clear decrease of specialized metabolites occurred in April and May, when temperature in the Northwestern Mediterranean starts to increase after winter (http://somlit.mio.univ-amu.fr), but no further variation occurred during the warmest period (August-October), indicating the fluctuation in the metabolomes might be due to sponge physiological responses rather than environmental parameters.

Although spatial variabilities at a scale of $200 \mathrm{~km}$ for $H$. fulva and H. mucosa metabolomes were significative, they were less intense than temporal variability. For the spatial study, different samplings were performed for both sponges at the same time (August 2014) to avoid any temporal bias. Metabolic changes due to spatial variation have been mostly associated to local adaptation to environmental conditions or genotypic selection across habitats (Moore et al. 2014). However, parameters driving spatial variability and spatial scales at which variation is the highest are still uncertain. In this study, we observed metabolomic differences between sampling sites, which were not dependent on the geographic scale studied (10 km compared to $>100 \mathrm{~km})$. However, the 
spatial scale studied remains considerably small, and thus larger geographical scales should be studied to assess distance decay in chemical fingerprint similarities (Noyer and Becerro 2012; Noyer et al. 2011). Other factors that could participate to spatial variations are biotic interactions (De Caralt et al. 2013) and the variable part of the sponge metabolome (Borchert et al. 2016; Schmitt et al. 2012). In a recent study on two zoantharian species collected in the tropical and temperate Brazilian Atlantic Ocean, intense metabolomic variations were observed at a large geographical scale (Costa-Lotufo et al. 2018). However, no clear data were reported for the precise taxonomic identification of the sampled species therefore questioning the conclusions given. Finally, spatial variations in the metabolome of marine invertebrate could result from a complex set of factors linked to environmental parameters of the sampling sites and the ecosystem structure. We thus suggest that temporal variations observed in sponge metabolomes would reflect some physiological changes such as the change in life-stages or stress episodes that affect strongly their metabolism, whilst spatial variations would be the result of a complex set of factors linked to the environment and more difficult to unravel.

Haplosclerids are an important group of sponges in terms of diversity and production of bioactive compounds. However, their taxonomy remains challenging due to major discrepancies between morphological and molecular data (Redmond et al. 2011; Tribalat et al. 2016). Molecular data indicates that many very distant related species have been placed in the genus Haliclona, that may even be polyphyletic (organisms that do not share a common ancestor), and re-examination of the systematics of the group Haploscerids is urgently needed (Tribalat et al. 2016; Redmond et al. 2011). Integrative taxonomy is a concept that is growing in popularity among taxonomists and consists in a combination of several independent datasets for the classification of species: morphology, anatomy, cytology, spicule shapes, reproduction, molecular data, chemical information etc. (Schlick-Steiner et al. 2009; Boury-Esnault et al. 2013; Ivanišević et al. 2011). Sponge chemotaxonomy was first proposed by Bergquist and co-workers in the late $60 \mathrm{~s}$ (Bergquist and Hartman 1969) however its popularity decreased in the last decades due to several pitfalls (Erpenbeck and van Soest 2006). Variability of metabolites is considered one of the major pitfalls of chemotaxonomy, since suitable chemotaxonomic markers require stability in their occurrence (Erpenbeck and van Soest 2006). In our case and even if we observed very clear patterns of intraspecific variation in both Haliclona species, contribution of intraspecific variability is much lower than interspecific variation, confirming the suitability of comparative and targeted metabolomics as a tool for assisting in the classification of some well groups of sponges. The main limit of its application for the genus Haliclona could be more 
associated to the correct taxonomic classification of this extremely complex group rather than to wrong insights from metabolomic analyses.

In conclusion, we found similar metabolic variations in both sponge species in April and May, suggesting common physiological responses that could be triggered by changes in environmental factors (e.g. start of reproduction related to thermal cues). This study draws attention to the importance of knowledge on the biological cycle as a key to better assess the associated metabolic changes of marine invertebrates. It also cast lights in production dynamics of specialized metabolites, which is relevant for marine natural product research and drug discovery. Finally, we show for the first time that despite marked intraspecific variations in the metabolomes of both sponge species, these are minor when compared to interspecific variations, indicating the suitability of using comparative metabolomics to help in Haliclona classification.

\section{Acknowledgements}

This project (Grant-Aid Agreement No. PBA/MB/16/01) is carried out with the support of the Marine Institute and is funded under the Marine Research Programme by the Irish Government. M.-A.T. received a Ph.D. scholarship from the French Ministry for Higher education and Research. Metabolomic analyses were performed on the MALLABAR platform (Funded by the CNRS, the Provence Alpes Côte d'Azur Region and the Total Foundation). S. Greff (IMBE Marseille, France) is acknowledged for his help in recording and analysing the metabolomic data.

Author contribution

Methodology and Formal Analysis, M.-A.T., T.P., M.R.; Validation, O.P.T.; Writing_-Original Draft Preparation, M.R.; Writing—Review \& Editing, O.P.T.; Supervision, T.P., O.P.T.; Project Administration, O.P.T.; Funding Acquisition, T.P., O.P.T.

\section{Funding}

This project (Grant-Aid Agreement No. PBA/MB/16/01) is carried out with the support of the Marine Institute and is funded under the Marine Research Programme by the Irish Government. The Ph.D. scholarship of M.-A. Tribalat has been funded by the French "Ministère de l'Enseignement supérieur, de la Recherche et de l'Innovation".

Compliance with ethical standards

Conflict of interest The authors declare that they have no conflict of interest. 
Ethical approval All applicable international, national, and/or institutional guidelines for the care and use of animals were followed. This article does not contain any studies with human participants performed by any of the authors.

\section{Electronic supplementary material}

Below is the link to the electronic supplementary material.

Supplementary material 1 (DOCX $320 \mathrm{~KB})$

\section{References}

Abdo, D. A., Motti, C. A., Battershill, C. N., \& Harvey, E. S. (2007). Temperature and spatiotemporal variability of salicylihalamide a in the sponge Haliclona sp. Journal of Chemical Ecology, 33, 1635-1645.

Agrawal, A. A., Hastings, A. P., Johnson, M. T. J., Maron, J. L., \& Salminen, J.-P. (2012). Insect herbivores drive real-time ecological and evolutionary change in plant populations. Science, 338, 113-116.

Alam, N., Bae, B. H., Hong, J., Lee, C.-O., Shin, B. A., Im, K. S., \& Jung, J. H. (2001). Additional bioactive lyso-PAF congeners from the sponge Spirastrella abata. Journal of Natural Products, 64, 533-535.

Alarif Walied, M., Abdel-Lateff, A., Al-Lihaibi Sultan, S., Seif-Eldin, A., N. \& Badria Farid, A. (2013). A new cytotoxic brominated acetylenic hydrocarbon from the marine sponge Haliclona sp. with a selective effect against human breast cancer. Zeitschrift für Naturforschung C, 68, 70-75.

Aoki, N., Yamamoto, K., Ogawa, T., Ohta, E., Ikeuchi, T., Kamemura, K., Ikegami, S., \& Ohta, S. (2013). Bromotheoynic acid, a brominated acetylenic acid from the marine sponge Theonella swinhoei. Natural Product Research, $27,117-122$.

Aratake, S., Trianto, A., Hanif, N., De Voogd, N. J., \& Tanaka, J. (2009). A new polyunsaturated brominated fatty acid from a Haliclona sponge. Marine Drugs, 7, 523-527.

Bergquist, P. R., \& Hartman, W. D. (1969). Free amino acid patterns and the classification of the demospongiae. Marine Biology, 3, 247-268. 
Blunt, J. W., Copp, B. R., Keyzers, R. A., Munro, M. H. G., \& Prinsep, M. R. (2017). Marine natural products. Natural Product Reports, 34, 235-294.

Borchert, E., Jackson, S. A., O’gara, F., \& Dobson, A. D. W. (2016). Diversity of natural product biosynthetic genes in the microbiome of the deep sea sponges Inflatella pellicula, Poecillastra compressa, and Stelletta normani. Frontiers in Microbiology, 7, 1027.

Bornancin, L., Bonnard, I., Mills, S. C., \& Banaigs, B. (2017). Chemical mediation as a structuring element in marine gastropod predator-prey interactions. Natural Product Reports, 34, 644-676.

Boury-Esnault, N., Lavrov, D. V., Ruiz, C. A., \& Pérez, T. (2013). The integrative taxonomic approach applied to porifera: A case study of the homoscleromorpha. Integrative and Comparative Biology, 53, 416-427.

Butler, A. J., Van Altena, I. A., \& Dunne, S. J. (1996). Antifouling activity oflyso-platelet-activating factor extracted from australian sponge Crella incrustans. Journal of Chemical Ecology, 22, 2041-2061.

Casapullo, A., Minale, L., \& Zollo, F. (1993). Paniceins and related sesquiterpenoids from the Mediterranean sponge Reniera fulva. Journal of Natural Products, 56, 527-533.

Casapullo, A., Scognamiglio, G., \& Cimino, G. (1997). Mucosin: A new bicyclic eicosanoid from the Mediterranean sponge Reniera mucosa. Tetrahedron Letters, 38, 3643-3646.

Cimino, G., \& De Stefano, S. (1977). New acetylenic compounds from the sponge Reniera fulva. Tetrahedron Letters, 18, 1325-1328.

Costa-Lotufo, L. V., Carnevale-Neto, F., Trindade-Silva, A. E., Silva, R. R., Silva, G. G. Z., Wilke, D. V., Pinto, F. C. L., Sahm, B. D. B., Jimenez, P. C., Mendonca, J. N., Lotufo, T. M. C., Pessoa, O. D. L., \& Lopes, N. P. (2018). Chemical profiling of two congeneric sea mat corals along the Brazilian coast: Adaptive and functional patterns. Chemical Communications, 54, 1952-1955.

De Caralt, S., Bry, D., Bontemps, N., Turon, X., Uriz, M.-J., \& Banaigs, B. (2013). Sources of secondary metabolite variation in dysidea avara (Porifera: Demospongiae): The importance of having good neighbors. Marine Drugs, 11,489 . 
De Goeij, J. M., Van Oevelen, D., Vermeij, M. J. A., Osinga, R., Middelburg, J. J., De Goeij, A. F. P. M., \& Admiraal, W. (2013). Surviving in a marine desert: The sponge loop retains resources within coral reefs. Science, 342, $108-110$.

De'ath, G. (2002). Multivariate regression trees: A new technique for modeling species-environment relationships. Ecology, 83, 1105-1117.

Dembitsky, V. M., Rezanka, T., \& Srebnik, M. (2003). Lipid compounds of freshwater sponges: Family Spongillidae, class Demospongiae. Chemistry and Physics of Lipids, 123, 117-155.

Duckworth, A. R., West, L., Vansach, T., Stubler, A., \& Hardt, M. (2012). Effects of water temperature and $\mathrm{pH}$ on growth and metabolite biosynthesis of coral reef sponges. Marine Ecology Progress Series, 462, 67-77.

Ereskovsky, A. V., Geronimo, A., \& Pérez, T. (2017). Asexual and puzzling sexual reproduction of the Mediterranean sponge Haliclona fulva (Demospongiae): Life cycle and cytological structures. Invertebrate Biology, 136, 403-421.

Erpenbeck, D., \& Van Soest, R. W. M. (2006). Status and perspective of sponge chemosystematics. Marine Biotechnology, 9, 2.

Ferrer, R. P., \& Zimmer, R. K. (2012). Community ecology and the evolution of molecules of keystone significance. The Biological Bulletin, 223, 167-177.

Ferrer, R. P., \& Zimmer, R. K. (2013). Molecules of keystone significancecrucial agents in ecology and resource management. BioScience, $63,428-438$.

Genta-Jouve, G., \& Thomas, O. P. (2013). Absolute configuration of the New 3 -epi-cladocroic acid from the Mediterranean sponge Haliclona Fulva. Metabolites, 3, 24-31.

Glassmire, A. E., Jeffrey, C. S., Forister, M. L., Parchman, T. L., Nice, C. C., Jahner, J. P., Wilson, J. S., Walla, T. R., Richards, L. A., Smilanich, A. M., Leonard, M. D., Morrison, C. R., Simbaña, W., Salagaje, L. A., Dodson, C. D., Miller, J. S., Tepe, E. J., Villamarin-Cortez, S., \& Dyer, L. A. (2016). Intraspecific phytochemical variation shapes community and population structure for specialist caterpillars. New Phytologist, 212, 208-219. 
Goulitquer, S., Potin, P., \& Tonon, T. (2012). Mass spectrometry-based metabolomics to elucidate functions in marine organisms and ecosystems. Marine Drugs, 10, 849-880.

Haas, A. F., Fairoz, M. F. M., Kelly, L. W., Nelson, C. E., Dinsdale, E. A., Edwards, R. A., Giles, S., Hatay, M., Hisakawa, N., Knowles, B., Lim, Y. W., Maughan, H., Pantos, O., Roach, T. N. F., Sanchez, S. E., Silveira, C. B., Sandin, S., Smith, J. E., \& Rohwer, F. (2016). Global microbialization of coral reefs. Nature Microbiology, 1, 16042.

Hay, M. E. (2009). Marine chemical ecology: Chemical signals and cues structure marine populations, communities, and ecosystems. Annual Review of Marine Science, 1, 193-212.

Hay, M. E. (2014). Challenges and opportunities in marine chemical ecology. Journal of Chemical Ecology, 40, 216-217.

He, Q., Sun, R., Liu, H., Geng, Z., Chen, D., Li, Y., Han, J., Lin, W., Du, S., \& Deng, Z. (2014). NMR-Based Metabolomic Analysis of Spatial Variation in Soft Corals. Marine Drugs, 12, 1876-1890.

Ivanisevic, J., Thomas, O. P., Pedel, L., Pénez, N., Ereskovsky, A. V., Culioli, G., \& Pérez, T. (2011). Biochemical trade-offs: Evidence for ecologically linked secondary metabolism of the sponge Oscarella balibaloi. PLoS ONE, 6, e28059.

Ivanišević, J., Perez, T., Ereskovsky, A. V., Barnathan, G., \& Thomas, O. P. (2011). Lysophospholipids in the Mediterranean sponge Oscarella tuberculata: Seasonal variability and putative biological role. Journal of Chemical Ecology, 37, 537-545.

Kelman, D., Benayahu, Y., \& Kashman, Y. (2000). Variation in secondary metabolite concentrations in yellow and grey morphs of the red sea soft coral Parerythropodium fulvum fulvum: Possible ecological implications. Journal of Chemical Ecology, 26, 1123-1133.

Kessner, D., Chambers, M., Burke, R., Agus, D., \& Mallick, P. (2008). ProteoWizard: Open source software for rapid proteomics tools development. Bioinformatics, 24, 2534-2536.

Kosmides, A. K., Kamisoglu, K., Calvano, S. E., Corbett, S. A., \& Androulakis, I. P. (2013). Metabolomic fingerprinting: Challenges and 
opportunities. Critical Reviews in Biomedical Engineering, 41, 205-221.

Kuhlisch, C., \& Pohnert, G. (2015). Metabolomics in chemical ecology. Natural Product Reports, 32, 937-955.

Li, D., Baldwin, I. T., \& Gaquerel, E. 2015. Navigating natural variation in herbivory-induced secondary metabolism in coyote tobacco populations using MS/MS structural analysis. Proceedings of the National Academy of Sciences, 112, E4147-E4155.

Lin, K., Yang, P., Yang, H., Liu, A.-H., Yao, L.-G., Guo, Y.-W., \& Mao, S.-C. (2015). Lysophospholipids from the Guangxi sponge Spirastrella purpurea. Lipids, 50, 697-703.

Loh, T.-L., \& Pawlik, J. R. (2014). Chemical defenses and resource trade-offs structure sponge communities on Caribbean coral reefs. Proceedings of the National Academy of Sciences of the United States of America, 111, 41514156.

López-Legentil, S., Bontemps-Subielos, N., Turon, X., \& Banaigs, B. (2006). Temporal variation in the production of four secondary metabolites in a colonial ascidian. Journal of Chemical Ecology, 32, 2079-2084.

López-Legentil, S., Bontemps-Subielos, N., Turon, X., \& Banaigs, B. (2007). Secondary metabolite and inorganic contents in Cystodytes sp. (Ascidiacea): Temporal patterns and association with reproduction and growth. Marine Biology, 151, 293-299.

Moore, B. D., Andrew, R. L., Külheim, C., \& Foley, W. J. (2014). Explaining intraspecific diversity in plant secondary metabolites in an ecological context. New Phytologist, 201, 733-750.

Müller, W. E. G., Klemt, M., Thakur, N. L., Schröder, H. C., Aiello, A., D'esposito, M., Menna, M., \& Fattorusso, E. (2004). Molecular/chemical ecology in sponges: Evidence for an adaptive antibacterial response in Suberites domuncula. Marine Biology, 144, 19-29.

Nishikawa, Y., Furukawa, A., Shiga, I., Muroi, Y., Ishii, T., Hongo, Y., Takahashi, S., Sugawara, T., Koshino, H., \& Ohnishi, M. (2015). Cytoprotective effects of lysophospholipids from sea cucumber Holothuria atra. PLoS ONE, 10, e0135701. 
Noyer, C., \& Becerro, M. A. (2012). Relationship between genetic, chemical, and bacterial diversity in the Atlanto-Mediterranean bath sponge Spongia lamella. Hydrobiologia, 687, 85-99.

Noyer, C., Thomas, O. P., \& Becerro, M. A. (2011). Patterns of chemical diversity in the Mediterranean sponge Spongia lamella. PLoS ONE, 6, e20844.

Nuzzo, G., Ciavatta, M. L., Villani, G., Manzo, E., Zanfardino, A., Varcamonti, M., \& Gavagnin, M. (2012). Fulvynes, antimicrobial polyoxygenated acetylenes from the Mediterranean sponge Haliclona fulva. Tetrahedron, 68, 754-760.

Ohta, S., Ogawa, T., Ohta, E., Ikeuchi, T., Kamemura, K., \& Ikegami, S. (2013). Petroacetylene, a new polyacetylene from the marine sponge Petrosiasolida that inhibits blastulation of starfish embryos. Natural Product Research, 27, 1842-1847.

Ortega, M. J., Zubía, E., Carballo, J. L., \& Salvá, J. (1996). Fulvinol, a new long-chain diacetylenic metabolite from the sponge Reniera fulva. Journal of Natural Products, 59, 1069-1071.

Page, M., West, L., Northcote, P., Battershill, C., \& Kelly, M. (2005). Spatial and temporal variability of cytotoxic metabolites in populations of the New Zealand sponge Mycale hentscheli. Journal of Chemical Ecology, 31, 11611174.

Patti, G. J., Tautenhahn, R., \& Siuzdak, G. (2012). Meta-analysis of untargeted metabolomic data: Combining results from multiple profiling experiments. Nature Protocols, 7, 508-516.

Paul, V. J., Arthur, K. E., Ritson-Williams, R., Ross, C., \& Sharp, K. (2007). Chemical defenses: From compounds to communities. The Biological Bulletin, 213, 226-251.

Paul, V. J., \& Van Alstyne, K. L. (1992). Activation of chemical defenses in the tropical green algae Halimeda spp. Journal of Experimental Marine Biology and Ecology, 160, 191-203.

Payo, D. A., Colo, J., Calumpong, H., \& De Clerck, O. (2011). Variability of non-polar secondary metabolites in the red alga Portieria. Marine Drugs, 9 , $2438-2468$. 
Peters, L., Wright, A. D., Krick, A., \& König, G. M. (2004). Variation of brominated indoles and terpenoids within single and different colonies of the marine bryozoan Flustra foliacea. Journal of Chemical Ecology, 30, 11651181.

Pham, N. B., Butler, M. S., Hooper, J. N. A., Moni, R. W., \& Quinn, R. J. (1999). Isolation of xestosterol esters of brominated acetylenic fatty acids from the marine sponge Xestospongia testudinaria. Journal of Natural Products, 62, 1439-1442.

Pohnert, G. (2004). Chemical defense strategies of marine organisms. In S. SCHULZ (Ed.), The chemistry of pheromones and other semiochemicals I. Berlin: Springer.

Proksch, P. (1994). Defensive roles for secondary metabolites from marine sponges and sponge-feeding nudibranchs. Toxicon, 32, 639-655.

Redmond, N. E., Raleigh, J., Van Soest, R. W. M., Kelly, M., Travers, S. A. A., Bradshaw, B., Vartia, S., Stephens, K. M., \& Mccormack, G. P. (2011). Phylogenetic relationships of the marine Haplosclerida (Phylum Porifera) employing ribosomal (28S rRNA) and mitochondrial (cox1, nad1) gene sequence data. PLoS ONE, 6, e24344.

Reverter, M., Perez, T., Ereskovsky, A. V., \& Banaigs, B. (2016). Secondary metabolome variability and inducible chemical defenses in the Mediterranean sponge Aplysina cavernicola. Journal of Chemical Ecology, 42, 60-70.

Rhoades, D. F. (1985). Offensive-defensive interactions between herbivores and plants: Their relevance in herbivore population dynamics and ecological theory. The American Naturalist, 125, 205-238.

Routaboul, J.-M., Dubos, C., Beck, G., Marquis, C., Bidzinski, P., Loudet, O., \& Lepiniec, L. (2012). Metabolite profiling and quantitative genetics of natural variation for flavonoids in Arabidopsis. Journal of Experimental Botany, 63, 3749-3764.

Sacristan-Soriano, O., Banaigs, B., \& Becerro, M. A. (2011). Relevant spatial scales of chemical variation in Aplysina aerophoba. Marine Drugs, 9, 24992513.

Sacristán-Soriano, O., Banaigs, B., \& Becerro, M. A. (2012). Temporal trends in the secondary metabolite production of the sponge Aplysina aerophoba. 
Marine Drugs, 10, 677-693.

Santín, A., Grinyó, J., Ambroso, S., Uriz, M. J., Gori, A., Dominguez-Carrió, C., \& Gili, J.-M. (2017). Sponge assemblages on the deep Mediterranean continental shelf and slope (Menorca Channel, Western Mediterranean Sea). Deep Sea Research Part I, 131, 75-86.

Schlick-Steiner, B. C., Steiner, F. M., Seifert, B., Stauffer, C., Christian, E., \& Crozier, R. H. (2009). Integrative taxonomy: A multisource approach to exploring biodiversity. Annual Review of Entomology, 55, 421-438.

Schmitt, S., Tsai, P., Bell, J., Fromont, J., Ilan, M., Lindquist, N., Perez, T., Rodrigo, A., SCHUPP, P. J., Vacelet, J., Webster, N., Hentschel, U., \& Taylor, M. W. (2012). Assessing the complex sponge microbiota: Core, variable and species-specific bacterial communities in marine sponges. The ISME Journal, $6,564-576$.

Shin, B. A., Kim, Y. R., Lee, I.-S., Sung, C. K., Hong, J., Sim, C. J., Im, K. S., \& Jung, J. H. (1999). Lyso-PAF analogues and lysophosphatidylcholines from the marine sponge Spirastrella abata as inhibitors of cholesterol biosynthesis. Journal of Natural Products, 62, 1554-1557.

Soares, A. R., Duarte, H. M., Tinnoco, L. W., Pereira, R. C., \& Teixeira, V. L. (2015). Intraspecific variation of meroditerpenoids in the brown alga Stypopodium zonale guiding the isolation of new compounds. Revista Brasileira de Farmacognosia, 25, 627-633.

Stanley, D. W. 2000. Eicosanoids in invertebrate signal transduction systems, Princeton: Princeton University Press.

Sugiura, T., Fukuda, T., Miyamoto, T., \& Waku, K. (1992). Distribution of alkyl and alkenyl ether-linked phospholipids and platelet-activating factorlike lipid in various species of invertebrates. Biochimica et Biophysica Acta (BBA), 1126, 298-308.

Ternon, E., Perino, E., Manconi, R., Pronzato, R., \& THOMAS, O. P. (2017). How environmental factors affect the production of guanidine alkaloids by the Mediterranean sponge Crambe crambe. Marine Drugs, 15, 181.

Tribalat, M.-A. 2016. Specialized metabolisms of Mediterranean sponges of genus Haliclona Grant, 1836. Nice: Université Côte d'Azur. 
Tribalat, M.-A., Marra, M. V., Mccormack, G. P., \& Thomas, O. P. (2016). Does the chemical diversity of the order Haplosclerida (Phylum Porifera: Class Demospongia) fit with current taxonomic classification? Planta Medica, 82, 843-856.

Vrablik, T. L., \& Watts, J. L. (2013). Polyunsaturated fatty acid derived signaling in reproduction and development: Insights from Caenorhabditis elegans and Drosophila melanogaster. Molecular Reproduction and Development, 80, 244-259.

Zhao, Q., Mansoor, T. A., Hong, J., Lee, C.-O., Im, K. S., Lee, D. S., \& Jung, J. H. (2003). New lysophosphatidylcholines and monoglycerides from the marine sponge Stelletta sp. Journal of Natural Products, 66, 725-728.

Zubía, E., Ortega, J., Luis Carballo, M., J. \& Salvá, J. (1994). Sesquiterpene hydroquinones from the sponge Reniera mucosa. Tetrahedron, 50, 81538160 . 